\title{
Analysis of Wear-Resisting Properties of a Sintered Sample Obtained from Steel X13 Machined Using EDM
}

\author{
E.V. Ageev ${ }^{1}$, S.V. Khardikov ${ }^{1, *}$, O.G. Loktionova ${ }^{1}$, and V.I. Kolmykov ${ }^{1}$ \\ ${ }^{1}$ Southwest State University, 305040, Kursk, Russian Federation
}

\begin{abstract}
The article presents the results of a study of the wear resistance of sintered specimens from electroerosive powder of steel X13, obtained in butyl alcohol. The friction coefficient was 0.950 , the width of the wear groove was $455.9 \mu \mathrm{m}$, the depth of the wear groove was $6 \mu \mathrm{m}$, the wear factor of the sample was $1.676 \times 10-6 \mathrm{~mm} 3 \mathrm{~N}-1 \mathrm{~m}-1$.
\end{abstract}

\section{Introduction}

Wear resistance is the property of a material to resist wear under certain conditions of friction, assessed by the reciprocal of the wear rate or wear rate. Wear resistance depends on the composition and structure of the material being processed, the initial hardness, roughness, and processing technology of the part, the state of the counterpart. There are also methods for increasing the wear resistance of parts by applying a special wear-resistant coating to the surface of the part. In this case, the wear resistance of an uncoated part can be much lower than that of a part with a wear-resistant coating.

Wear resistance should be judged by various criteria, and the following subordinate concepts should be introduced as characteristic:

1. Efficiency. The material must be able to withstand high loads at all temperatures and economical lubrication, that is, at boundary friction, at speeds ranging from zero to maximum values and changing directions of movement.

2. The tendency to seize, that is, the tendency to weld surface particles with the mating material, should be as low as possible when working with the liner material, even when, due to the point mating and the high load from the ingress of foreign particles or particles between the abrasion of the sliding surface, temporary significant local temperature rises will occur.

3. Good break-in ability. Under given stress, motion, and lubrication conditions, a solid, mirror-like work surface with good oil adhesion should quickly form. The material should be polished.

4. Good backup performance. In the event of a temporarily insufficient or temporary lack of lubrication, the material should be able to withstand the specified workload for some time without excessive wear.

* Corresponding author: hardikov1990@mail.ru 
5. Wear should be carried out so that only the smallest particles are separated from the surface, which, falling between the shaft journal and the liner, do not interfere with the operation; when worn, particles must never be crumbled.

The widespread use of X13 steel in various industries leads to a large accumulation of its waste that requires processing. Currently, there are many ways to recycle metal waste. However, the disadvantages of the known methods are increased energy consumption, multi-stage process [1-6].

The most promising method for processing metal waste is the method of electroerosive dispersion (EED), which is distinguished by the environmental friendliness of the process and relatively low energy consumption.

Comprehensive theoretical and experimental studies are needed to develop technologies for the practical use of powder materials obtained from X13 alloy waste and to evaluate the efficiency of their use. The aim of this work is to analyze the wear resistance characteristics of a sintered specimen made of alloy X13 electroerosive materials.

\section{Materials and Methods}

To obtain electroerosive materials, waste steel X13 was loaded into the reactor of the electroerosive dispersion unit, filled with a working fluid - butyl alcohol. In this case, the following parameters of the installation were used: - pulse repetition rate $95 \ldots 105 \mathrm{~Hz}$; voltage at the electrodes $100 \ldots 110 \mathrm{~V}$; - the capacitance of the capacitors is $55 \mu \mathrm{F}$ [7-10]. As a result of electric spark discharges, dispersed particles were formed in the contact zone of the electrodes and with the dispersed waste material, which was then subjected to pressing and sintering. The samples obtained were examined by various methods. The coefficient of friction and the rate of wear of the surface of the samples and counter body was measured on an automated Tribometer friction machine according to the standard "ball disk" test scheme. The tests were carried out in air at a load of $5 \mathrm{~N}$ and a linear velocity of $15 \mathrm{~cm} / \mathrm{s}$, a radius of curvature of wear of $3 \mathrm{~mm}$, and a friction path of 500 meters.

The powder was consolidated by the method of spark plasma sintering using a spark plasma sintering system SPS 25-10 (Thermal Technology, USA) according to the scheme shown in Figure 1. The starting material was placed in a graphite matrix placed under a press in a vacuum chamber. Electrodes, integrated into the mechanical part of the press, supply an electric current to the matrix and create spark discharges between the sintered material particles, ensuring intense interaction. The powder consolidation process is shown schematically in Figure 2. 


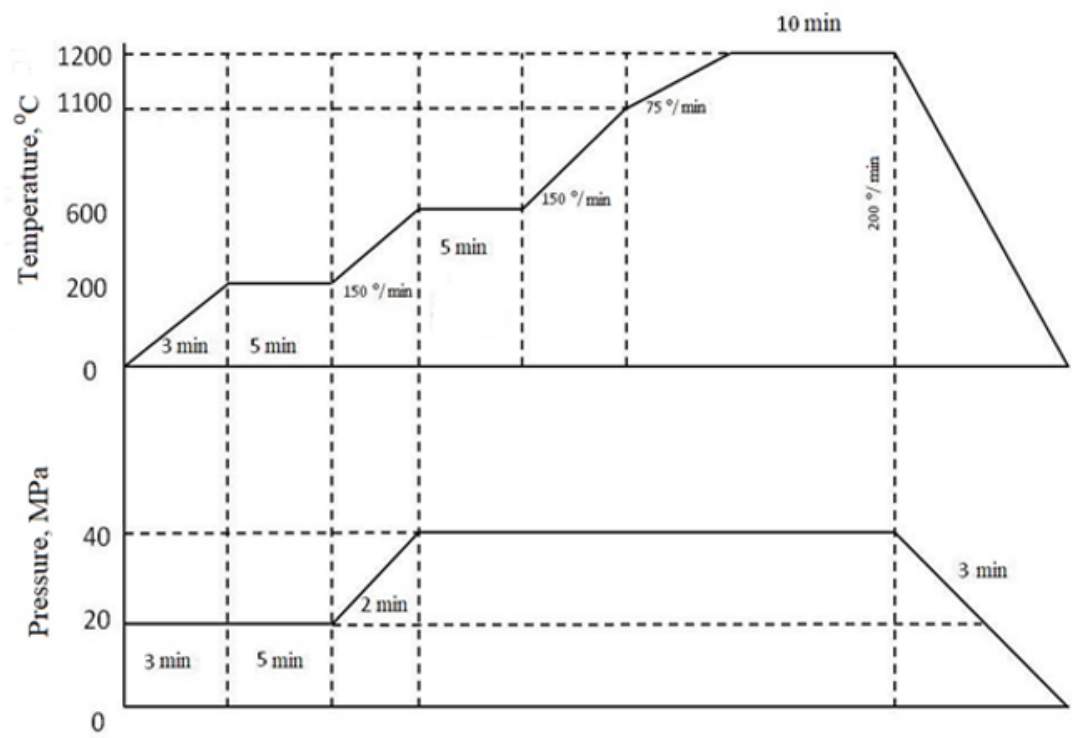

Fig. 1. Consolidation of powders by the method of spark plasma sintering (diagram)

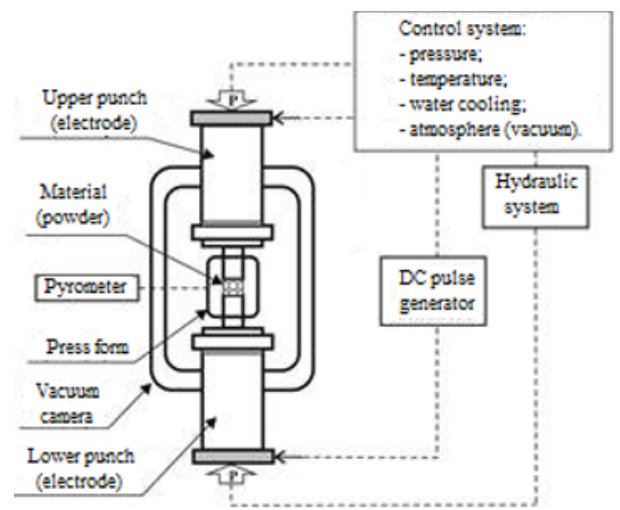

A

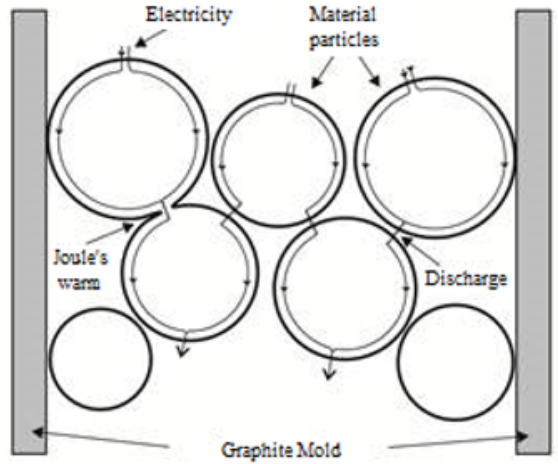

Fig. 2. Spark plasma sintering technology: A - schematic diagram of SPS synthesis; B - general heating scheme according to the SPS method

Technology advantages: uniform heat distribution over the sample; high density or controlled porosity; binders are NOT required; uniform sintering of homogeneous and dissimilar materials; short cycle time; production of a part immediately in its final form and obtaining a profile close to the desired one.

The coefficient of friction and the rate of wear of the surface of the samples and counter body was measured on an automated friction machine (Tribometer, CSM Instruments, Switzerland), controlled by a computer (Figure 3), according to the standard "ball-disk" test scheme (Figure 4). These tests allow the use of the Hertz model, they comply with the international standards ASTM G99-959 DIN50324 and can be used to assess the wear resistance of a specimen and counter body. 


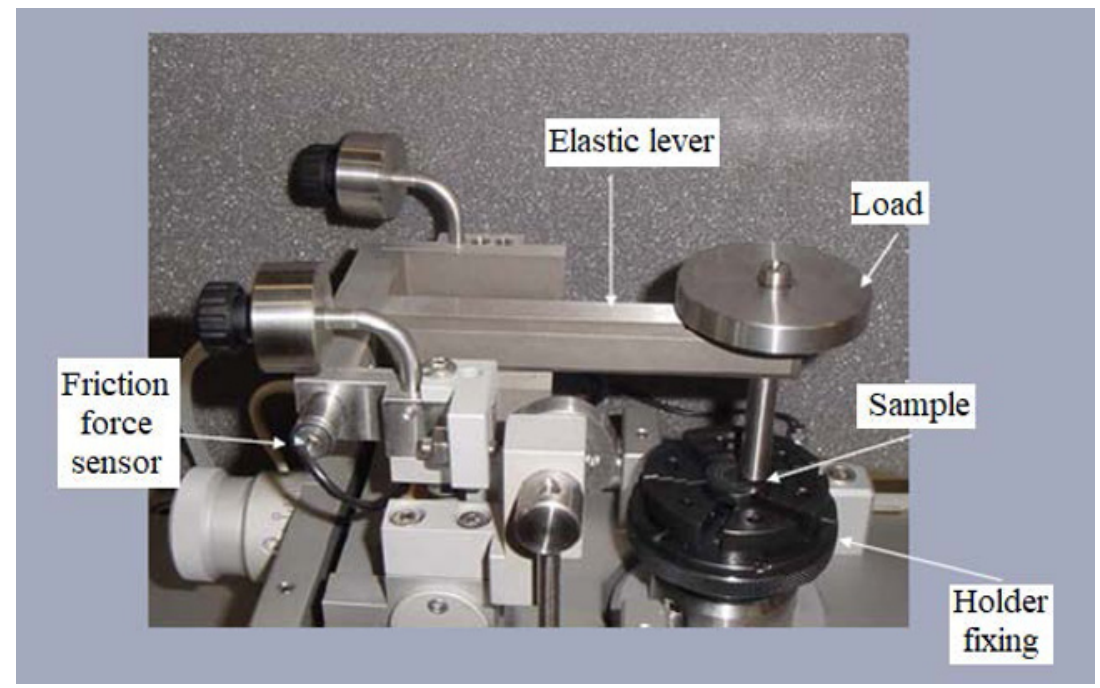

Fig. 3. Diagram of an automated friction machine (Tribometer, CSM Instruments, Switzerland)

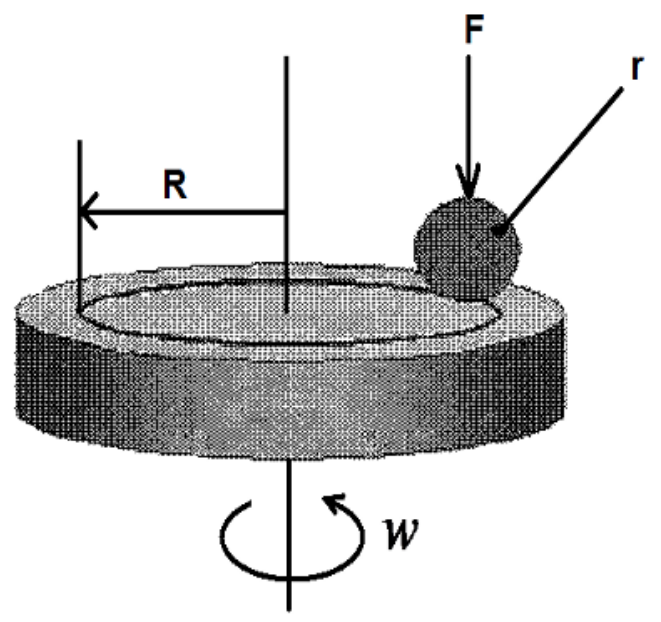

Fig. 4. Standard test scheme "ball-disk", - radius of curvature of wear; - radius

The samples were installed in a holder, a rod was fixed perpendicular to the plane of the sample, at the end of which there was a ball $6 \mathrm{~mm}$ in diameter $\mathrm{Al}_{2} \mathrm{O}_{3}$ (aluminum oxide). By adjusting the displacement sensor, the radius of curvature of the wear was selected, another sensor compensated for the friction force and made it possible to set the value of the friction coefficient at a certain point in time.

\section{Results}

The research results are presented below, namely: the optical image of the wear spot of the counter body (ball) after repeated passes over the test surface of the sample (Fig. 5), the zone of mechanical contact between the counter body and the sample (Fig. 6), the profile of the wear groove of the sample surface (Fig. 7) and a summary table of the tribological characteristics of the sample (Table 1). 


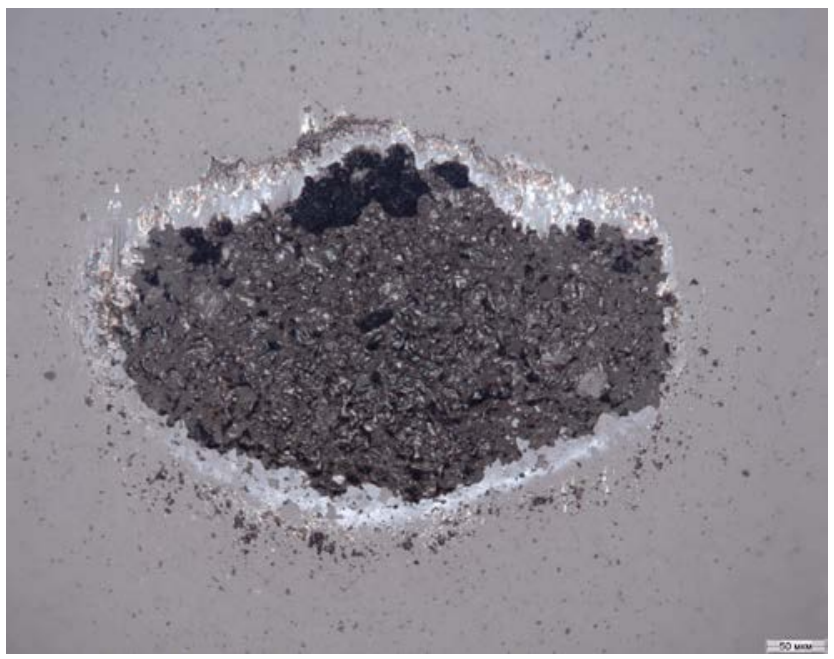

Fig. 5. Optical image of the counterbody wear spot

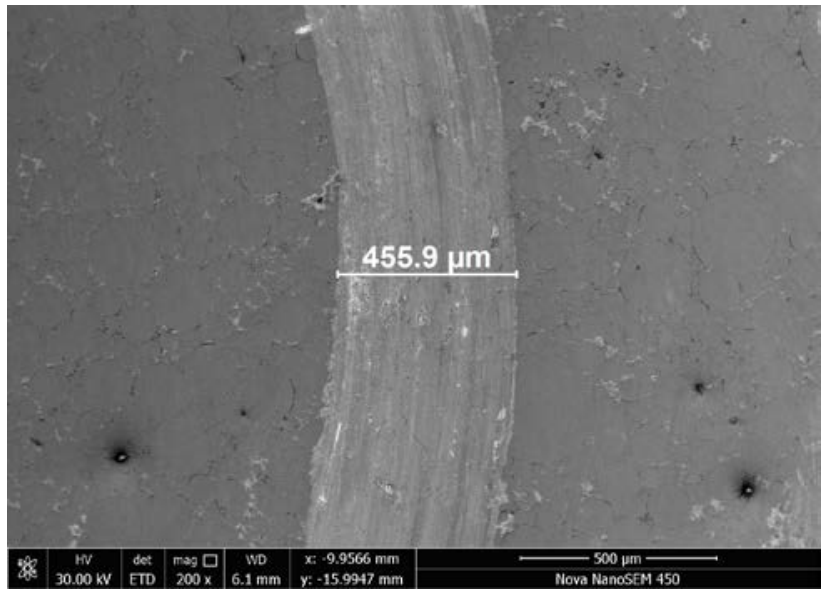

Fig. 6. Mechanical contact area counter body - sample

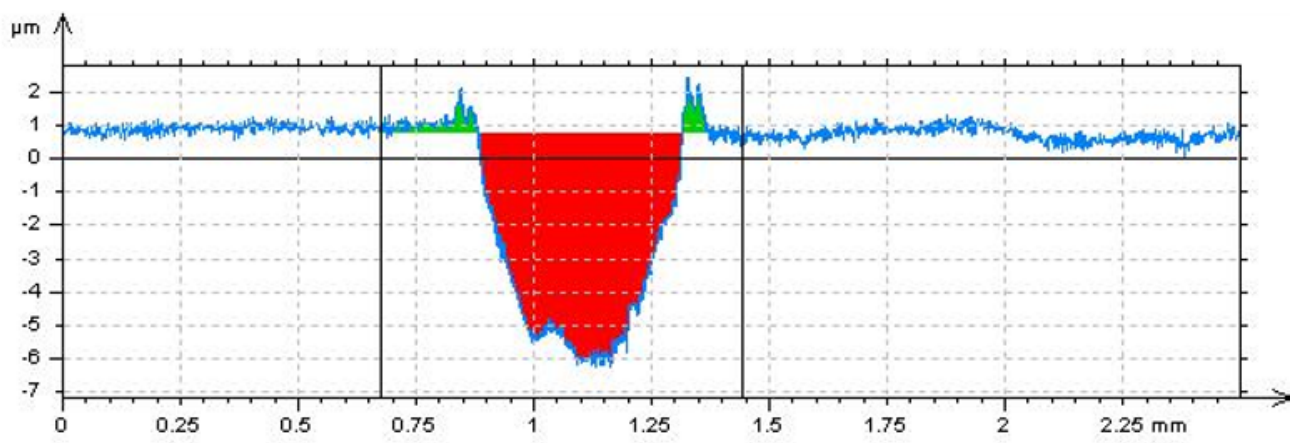

Fig. 7. Profile of the wear groove of the sample surface 
Table 1. Tribological characteristics of the test samples

\begin{tabular}{|c|c|c|c|c|c|c|c|}
\hline \multicolumn{5}{|c|}{ Friction coefficient $(\mu)$} & \multirow[b]{2}{*}{$\begin{array}{c}\text { Vickers } \\
\text { hardness } \\
(\mathrm{GPa})\end{array}$} & \multirow{2}{*}{$\begin{array}{l}\text { Wear factor of } \\
\text { the statistical } \\
\text { partner, } \mathrm{mm}^{3} \times \\
\begin{array}{c}\mathrm{H}^{-1} \times \mathrm{m}^{-1} \mathrm{x} \\
\times 10^{-5}\end{array}\end{array}$} & \multirow{2}{*}{$\begin{array}{c}\text { Factor } \\
\text { sample wear, } \\
\mathrm{mm}^{3} \times \mathrm{H}^{-1} \times \\
\mathrm{m}^{-1} \times 10^{-5}\end{array}$} \\
\hline Elementary & $\min$ & $\max$ & mean & $\begin{array}{l}\text { Std. } \\
\text { dev. }\end{array}$ & & & \\
\hline 0,243 & 0,243 & 1,002 & 0,950 & 0,071 & 4,518 & 0,019 & 1,676 \\
\hline
\end{tabular}

\section{Conclusion}

The following tribological characteristics of sintered samples from electroerosive powder of steel X13 obtained in butyl alcohol were experimentally established:

1. The width of the wear groove was $455.9 \mu \mathrm{m}$;

2. The average value of the coefficient of friction was 0.950 .

3. The wear factor of the sample and the statistical partner was $1.676 \times 10^{-5} \times \mathrm{mm}^{3} \times \mathrm{H}^{-1}$ $\times \mathrm{m}^{-1}$ and $0.019 \times 10^{-5} \times \mathrm{mm}^{3} \times \mathrm{H}^{-1} \times \mathrm{m}^{-1}$, respectively.

The presented research results will allow determining the most rational area of application of the obtained sintered products.

The work was supported by a scholarship of the President of the Russian Federation for young scientists and graduate students (SP-945.2019.1).

\section{References}

1. S.B. Maslenkov, All materials. Encyclopedic Reference 1, 18 (2007).

2. V.A. Falkowski, F.I. Falkowski, V.S. Panov, Non-Ferrous Metal. 10, 85 (2007).

3. T.B. Ershova, M.I. Dvornik, A.V. Zaitsev, Composite. Nanostruct. 2, 40 (2011).

4. N. Hertel, Ferrous Metal. No 2, 50 (2012).

5. Shishkovskii I V, Petrov A L, Makarenko A G 1999 Combustion, Explosion, and Shock Waves 35 166-170

6. Z. Qiao, X. Ma, W. Zhao, H. Tang, B. Zhao, J. of All. and Comp., 462, 416-420 (2008)

7. E.V. Ageev, A.V. Kirichek, A.Yu. Altuhov, E.V. Ageeva, J. Nano- Electron. Phys. 6 3, 03001 (2014).

8. E.V. Ageeva, E.V. Ageev, N.M. Horyakova, V.S. Malukhov, J. Nano- Electron. Phys. 6 3, 03011 (2014).

9. E.V. Ageev, S.V. Khardikov, E.A. Vorobyev, A.A. Sysoev, MATEC Web of Conf., 298, 00127 (2019)

10. E.V. Ageev, The patent 2449859, the Russian Federation, C2, B22F9/14. No 2010104316/02; appl. 08.02.2010; publ. 10.05.2012. - 4 p. 